\title{
SPECIAL ISSUE EDITORIAL: INFORMATION TECHNOLOGIES FOR SMART CITY DEVELOPMENT (CIB WORLD BUILDING CONGRESS 2019 SPECIAL ISSUE)
}

PUBLISHED: December 2020 - October 2021

DOI: $10.36680 /$ j.itcon.2021.037

Francis $\mathrm{Siu}, \mathrm{PhD}$,

Managing Guest Editor, Assistant Professor, Department of Building and Real Estate, The Hong Kong Polytechnic University, Hung Hom, Kowloon, Hong Kong, China;

francis.siu@polyu.edu.hk

Hung-Lin Chi, PhD,

Guest Editor, Assistant Professor, Department of Building and Real Estate, The Hong Kong Polytechnic University, Hung Hom, Kowloon, Hong Kong, China;

hung-lin.chi@polyu.edu.hk

Hsi-Hsien Wei, PhD,

Guest Editor, Assistant Professor, Department of Building and Real Estate, The Hong Kong Polytechnic University, Hung Hom, Kowloon, Hong Kong, China;

hsi-hsien.wei@polyu.edu.hk

Minkoo Kim, PhD,

Guest Editor, Assistant Professor, Department of Architectural Engineering, Chungbuk National University. Former Assistant Professor, Department of Building and Real Estate, The Hong Kong Polytechnic University, Hung Hom, Kowloon, Hong Kong, China.

joekim@chungbuk.ac.kr

SUMMARY: On 17-21 June 2019, the Conseil International du Bâtiment (CIB) World Building Congress 2019 (WBC 2019) on Constructing Smart Cities took place in The Hong Kong Polytechnic University with the host being the Department of Building and Real Estate. This triennial international congress facilitated the in-depth exchange of research ideas on the aspects of smart construction using information technologies, including "smart transportation and mobility", and "smart planning, design, construction". Besides, the CIB Working Commission Group WC78 emphasised the importance of using the up-to-date information technologies for smart city development. The fruitful discussions fostered the close collaboration between academia and practitioners. Built upon the research works presented in the CIB WBC 2019, outstanding conference papers were selected and invited for enriching the contents which were accepted for publication after rigorous peer review in this special issue of "Journal of Information Technology in Construction" which aims to promote the research interest of the information technologies in smart city development. Highlights of each paper is provided below for readers' reference.

KEYWORDS: Information technologies, Smart city development

REFERENCE: Francis Siu, Hung-Lin Chi, Hsi-Hsien Wei, Minkoo Kim (2021). EDITORIAL: Information technologies for smart city development (CIB World Building Congress 2019 special issue). Journal of Information Technology in Construction (ITcon), Special issue: 'CIB World Building Congress 2019: Constructing Smart Cities', Vol. 26, pg. 697-699, DOI: 10.36680/j.itcon.2021.037

COPYRIGHT: () 2021 The author(s). This is an open access article distributed under the terms of the Creative Commons Attribution 4.0 International (https://creativecommons.org/licenses/by/4.0/), which permits unrestricted use, distribution, and reproduction in any medium, provided the original work is properly cited. 


\section{PAPER 1: IDENTIFYING ROADSIDE OBJECTS IN MOBILE LASER SCANNING DATA USING IMAGE-BASED POINT CLOUD SEGMENTATION}

The opening paper was presented by Uggla and Horemuz (2021). They introduced a sensor-fused segmentation algorithm integrating camera captured images and laser scanned point clouds to detect the game fences of roadside, which improved a nearly invisible roadside object detection performance for practical smart infrastructure maintenance. The authors proposed image-based point cloud segmentation in two stages: firstly, extract object of interest through semantic segmentation in images and identified corresponding points on the point cloud through perspective projections. Secondly, geometric processing and refinement are applied to the identified points to filter out further and recognize game fence regions. They have explored the algorithm performance through practical mobile laser scanning and imaging data collected by a moving vehicle on the road. Further evaluations, in terms of accuracy and computational efficiency, are carried out and reported in this research work. Comparing to ground truth, the proposed image-based point cloud segmentation outperformed conventional PointNet processing with higher accuracy and efficiency. The authors also discussed the flexibility of the proposed algorithm, which is also compatible with photogrammetry applications. A future extension is set to generalise the object detection type for extracting holistic smart semantic infrastructure information.

\section{PAPER 2: INTERPRETED OPEN DATA EXCHANGE BETWEEN ARCHITECTURAL DESIGN AND STRUCTURAL ANALYSIS MODELS}

The second paper was presented by Sibenik and Kovacic (2021). A novel data management framework is proposed to efficiently support the model-based data exchange between architectural design and structural analysis tools based on classification, interpretation and automation. Firstly, the authors introduced domain-specific classifications and inter-domain interpretations based on the review of existing classification standards, software tools, and data exchange standards. By identifying the relationships between two proprietary building models for data interpretations, data exchange process can be automated. Finally, a case study was presented to demonstrate the useability of the new system architecture. The domain-specific models in coping with the data format in central storages can be prepared. This proposed data management framework relieves the software developers from sofar-unsuccessful implementation of complex inter-domain interpretations which are designed specifically for each software tool. The practitioners such as designers and engineers will be able to smartly control the data exchange between the complex building models.

\section{PAPER 3: SCANNING AND DATA CAPTURING FOR BIM-SUPPORTED RESOURCES ASSESSMENT: A CASE STUDY}

The third paper was given by Kovacic and Honic (2021). They presented a data capturing method for generating as-built BIM model using laser scanning and ground penetrating radar (GPR) sensors. An integrated data assessment and modelling (IDAM) method which allows the generation of information-rich as-built BIM model was newly proposed based on the integration of two sensors. The key idea of using GPR sensors in generating asbuilt BIM models is that current use of laser scanning is only focused on capturing the geometric information without capturing the material information of a target building that is necessary for generating detailed and semantic as-built BIM model. Particularly, GPR sensors were used in this study to identify the material composition of building elements. For validation, a real case study on a single-story office and lab facility of Vienna University of Technology was conducted to validate the IDAM method and its usability. The case study results proved that the usage of GPR sensors can accurately and smartly detect the material compositions of building elements and can be combined with its corresponding geometric information of the buildings. The authors discussed the necessity of further improvements in automatic detection of material information captured by the GPR sensors and use of machine learning algorithms to increase the material detection accuracy in existing buildings. The proposed IDAM with the three improvements is expected to be popularly applied in existing buildings thanks to the integration of laser scanner and GPR sensor.

\section{PAPER 4: DEFINING WORK-ZONES FOR RESOURCE ALLOCATION IN HONG KONG PUBLIC HOUSING PROJECT CONSTRUCTION USING HEURISTIC RULES AND OPERATIONS SIMULATION}

The fourth paper was compiled by Lin et al. (2021). The authors focused on improving the planning strategies of worker allocation in building construction using smart construction technologies. They highlighted the repetitive nature of standard building works when constructing the concrete superstructures. They further examined the 
importance of defining work-zones to maintain the continuity of resource usage when performing the repetitive works at workface level. Three heuristic rules were proposed for evaluating the work zone definition schemes given by the project managers. The rules were "lengths of work-zone dividing line", "fluctuations of daily duration", and "utilisation rates of resource". With the advancement of construction technologies, the lengths of work-zone dividing lines, fluctuations of daily duration, and utilisation rates of resources can be accurately determined using modern computers, rather than based on personal experience. The lengths of work-zone dividing line can be derived using BIM technologies, while the fluctuations of daily duration and utilisation rates of resources can be analysed based on the resource schedules formulated using computer simulation. Furthermore, a practical case study of 40-storey building construction was given to illustrate the method application of the proposed rules. These new rules, which captured the planning wisdom of builders, can be smartly applied in practice thanks to the development of information technologies.

\section{PAPER 5: AUTOMATED OPTIMUM VISUALISATION SYSTEM FOR CONSTRUCTION DRAWING READING}

The fifth paper was presented by Swanborough et al. (2021). The authors attempted to solve the current problem for construction workers in implementing the task of reading drawings on job sites. To tackle this problem, a prototyped smart system was proposed to automatically change the visualisation parameters such as line thickness and line colour based on the colour and texture of the current surface so that the drawings are visible under any conditions. The proposed method includes algorithms to compute and update visualisation parameters given an image. In order to verify the proposed system, the authors conducted tests on eight subjects with four background surfaces commonly found on site were performed. The test results prove that the proposed system can enhance the recognition ability for construction workers in reading construction drawings regardless of image and light conditions. It is envisaged that the proposed visualisation solution can improve the productivity of the worker in reading drawings on job sites.

We hope that the readers enjoy reading the above selected research articles focused on creating and applying smart information technologies in construction. Lastly, the editorial board of this special issue would like to acknowledge the unreserved support and technical assistance given by the followings: the editorial board and administrative staff of "Journal of Information Technology in Construction", the CIB WBC 2019 host organisation (academic staff in the Department of Building and Real Estate, The Hong Kong Polytechnic University), the authors and reviewers who have generously contributed to this special issue, and the research students associated with the managing guest editor, Dr. Francis Siu (Dr. Ling Chen, Mr. King-Chi Lo, Mr. Kyle Qi, and Mr. Arthur To). Anyone wishing to join the Editorial Board of the Journal please contact Professor Robert Amor at his email address trebor@cs.auckland.ac.nz.

\section{REFERENCES}

Kovacic I, Honic M (2021). Scanning and data capturing for BIM-supported resources assessment: a case study, ITcon Vol. 26, Special issue CIB World Building Congress 2019: Information technology of smart city development, pg. 624-638, https://doi.org/10.36680/j.itcon.2021.032

Lin Z, Siu F, Chan D, Lau D (2021). Defining work-zones for resource allocation in Hong Kong public housing project construction using heuristic rules and operations simulation, ITcon Vol. 26, Special issue CIB World Building Congress 2019: Information technology of smart city development, pg. 657-680, https://doi.org/10.36680/j.itcon.2021.035

Sibenik G, Kovacic I (2021). Interpreted open data exchange between architectural design and structural analysis models, ITcon Vol. 26, Special issue CIB World Building Congress 2019: Information technology of smart city development, pg. 39-57, https://doi.org/10.36680/j.itcon.2021.004

Swanborough J, Kim M-K, Agapaki E, Brilakis I (2021). Automated optimum visualization system for construction drawing reading, ITcon Vol. 26, Special issue CIB World Building Congress 2019: Information technology of smart city development, pg. 681-696, https://doi.org/10.36680/j.itcon.2021.036

Uggla G, Horemuz M (2020). Identifying roadside objects in mobile laser scanning data using image-based point cloud segmentation, ITcon Vol. 25, Special issue CIB World Building Congress 2019: Information technology of smart city development, pg. 545-560, https://doi.org/10.36680/j.itcon.2020.031 